\title{
Refractory Kaposi Sarcoma
}

National Cancer Institute

\section{Source}

National Cancer Institute. Refractory Kaposi Sarcoma. NCI Thesaurus. Code C156474.

Kaposi sarcoma that is resistant to treatment. 